\title{
SUITABILITY EVALUATION OF SHALLOW NET CAGE CULTURE BASED ON INTERACTION MATRIX - A CASE STUDY OF XINCUN LAGOON, HAINAN, CHINA
}

\author{
FANG, X. ${ }^{1,2}-$ LI, X. Y. ${ }^{1}-$ HAO, C. L. ${ }^{1}-$ ZHANG, D. R. ${ }^{1}-$ WANG, J. C. ${ }^{1}-$ ZHANG, Y. F. ${ }^{1 *}$ \\ ${ }^{1}$ Second Institute of Oceanography, Ministry of Natural Resources \\ 36 BaochubeiLu Rd., Hangzhou 310012, P. R. China \\ (phone: +86-571-8196-3336; fax: +86-571-8805-4750) \\ ${ }^{2}$ School of Geography and Ocean Science, Nanjing University \\ No.163 Xianlin Rd., Qixia District, Nanjing, Jiangsu 210093, P. R. China \\ *Corresponding author \\ e-mail:fangx@sio.org.cn
}

(Received $2^{\text {nd }}$ Feb 2019; accepted $21^{\text {st }}$ Mar 2019)

\begin{abstract}
Shallow water cage culture is the main marine activity of Xincun Lagoon, Hainan. However, the continuous growth of aquaculture activities not only aggravates the deterioration of the ecological environment of Lagoon, but also affects the healthy development of mariculture. Suitability analysis on net cage mariculture can reduce the pressure of marine ecological environment, increase the yield of aquaculture and alleviate the conflict between different marine activities to a certain extent. However, the interaction of various factors affecting the suitability evaluation of mariculture constitutes a complex system, and the traditional method of weight determination cannot fit the actual situation well. For this reason, this paper attempts to introduce the interaction matrix of rock engineering systems (RES) to evaluate the weight of each index. At the same time, a multi-criteria decision analysis (MCDA) model based on GIS is established. Finally, a continuous graph of the suitability change of shallow sea cage culture in Xincun Lagoon is obtained. The results show that (1) the entrance area of Lagoon is the most suitable area for cage culture in shallow water; (2) the evaluation results are in agreement with the actual situation and previous studies, and the weight determination method is reasonable and feasible.
\end{abstract}

Keywords: mariculture, suitability analysis, rock engineering systems, GIS, multivariate analysis, ecosystem approach

\section{Introduction}

Shallow sea cage culture is the main production activity of Xincun Lagoon, Hainan. However, the continuous growth of aquaculture activities not only aggravates the deterioration of Lagoon ecological environment, but also affects the healthy development of mariculture (Yin et al., 2018). In 2016 and 2017, widespread cagecultured fish deaths occurred continuously in Xincun Lagoon. After field investigations, the main reason was found to be that the fish were hypoxic due to the high density of fish cultures, and the excessive feed also caused eutrophication of the water body. A recent study showed that the amount of $\mathrm{TN}$ and $\mathrm{TP}$ discharged from cage culture in shallow water accounts for more than $50 \%$ of the total discharge of all marine activities (Fang et al., 2018).

With China's attention to eco-environmental protection, the State Oceanic Administration proposed the Blue Bay Remediation Action Plan to restore the ecological environment quality in the Gulf region. Some researches of FAO also show that the ecosystem approach to aquaculture (EAA) and spatial planning are both important tools for sustainable aquaculture (FAO, 2015). Therefore, it is necessary to 
formulate scientific aquaculture planning to reduce the pressure of aquaculture activities on the ecosystem of Xincun Lagoon, to improve the production of mariculture, and to alleviate the conflict between different marine activities. In view of the above objectives, this paper evaluates the suitability of shallow sea cage culture by taking Lagoon as an example, selecting appropriate parameters, using interaction matrix to calculate the weight and combining with Geographic Information System (GIS) to do multi-criteria decision analysis.

Since the end of the 1980s, the academia has begun to study the site selection of aquaculture and guide the actual management of government departments (Parker et al., 1998). For example, when Joaquin (2011) chose the aquaculture area for oysters in the Caribbean Sea, they used multi-factor evaluation method and analytic hierarchy process to calculate the weight of each index and obtain the result of suitability evaluation by combining four kinds of indicators including the internal environment of sea area, the external environment of sea area, the transportation convenience and the social and economic conditions. Dapueto et al. (2015) proposed the spatial multi-criteria evaluation (SMCE) method to determine the area suitable for offshore medium-sized fish farms in Liguria, Italy. The result shows that the SMCE method has good practical significance. Yin et al. (2018) established a high-resolution hydrodynamic model to increase the availability of data, selected environmental and socio-economic indicators and used Multi-Criteria Decision Analysis (MCDA) to determine the suitable aquaculture sites in the coastal areas of Menai Strait.

Considering the complexity of mariculture suitability indicators, this study intends to use interaction matrix to determine the weight of indicators. This method was first proposed by Hudson (1989) to study the problem of rock engineering system (RES). Then it was developed with Mazzoccola to make it more suitable for the application of soft science (Mazzoccola and Hudson, 1996). The basic idea is to treat rock engineering as a complete system. The interaction matrix is constructed by enumerating the variables related to the system, and the interaction between variables is quantitatively evaluated by matrix coding. This method considers not only the influence of each parameter on the system, but also the contribution of the interaction between parameters to the whole system. Compared to other methods, such as Analytic Hierarchy Process, it is more suitable for solving the complex problems of interaction and coupling among various factors (Wu et al., 2011). Subsequently, this method was applied to many disciplines, such as ecosystem assessment (Velasco et al., 2006) and gas spontaneous combustion (Zhou et al., 2017), and so on.

\section{Preparation}

\section{Conceptual framework}

In this paper, taking Xincun Lagoon as an example and referring to the current research situation in related fields at home and abroad, we select appropriate indicators according to local conditions. Considering the interlaced relationship between indicators, it is difficult for the general method of determining indicators, such as analytic hierarchy process, to reflect the relative importance of indicators perfectly. In this paper, the concept of interaction matrix is introduced and the weight values of indicators are calculated. The spatial distribution of the results of each index is quantified by using the Geographic Information System (GIS) method. Then, the multi-criteria decision 
analysis method is used to perform linear superposition in ArcGIS software. Finally, the spatial distribution map of the suitability of shallow sea cage culture is obtained.

\section{Study region and area}

Xincun Lagoon $\left(\mathrm{N} 18^{\circ} 22^{\prime}-18^{\circ} 47^{\prime}\right.$, E109 $\left.45^{\prime}-110^{\circ} 08^{\prime}\right)$ is located in the southeast part of Xincun Town, Lingshui County, Hainan Province, China, as shown in Fig. 1. Its East-West width is $5.1 \mathrm{~km}$, its north-south length is $4.5 \mathrm{~km}$, and its area is $24 \mathrm{~km}^{2}$. It is a medium-sized sand bar-tidal inlet-lake system, and its ebb-flow tidal delta is relatively developed. According to the analysis of remote sensing images, the area of Lagoon decreased by $1.69 \mathrm{~km}^{2}$ in the 25 years from 1988 to 2013. There are many marine activities around the Lagoon, including use of the sea areas for tourism, town, land aquaculture pond and shallow sea cage culture, among which the pollutants discharged from shallow sea cage culture account for more than 50\%. To this end, the local government has formulated the Beach planning of aquaculture waters in Lingshui Li Autonomous County (2018-2030), which sets a ceiling on the area of cage culture, but does not make recommendations on specific suitable areas for aquaculture.
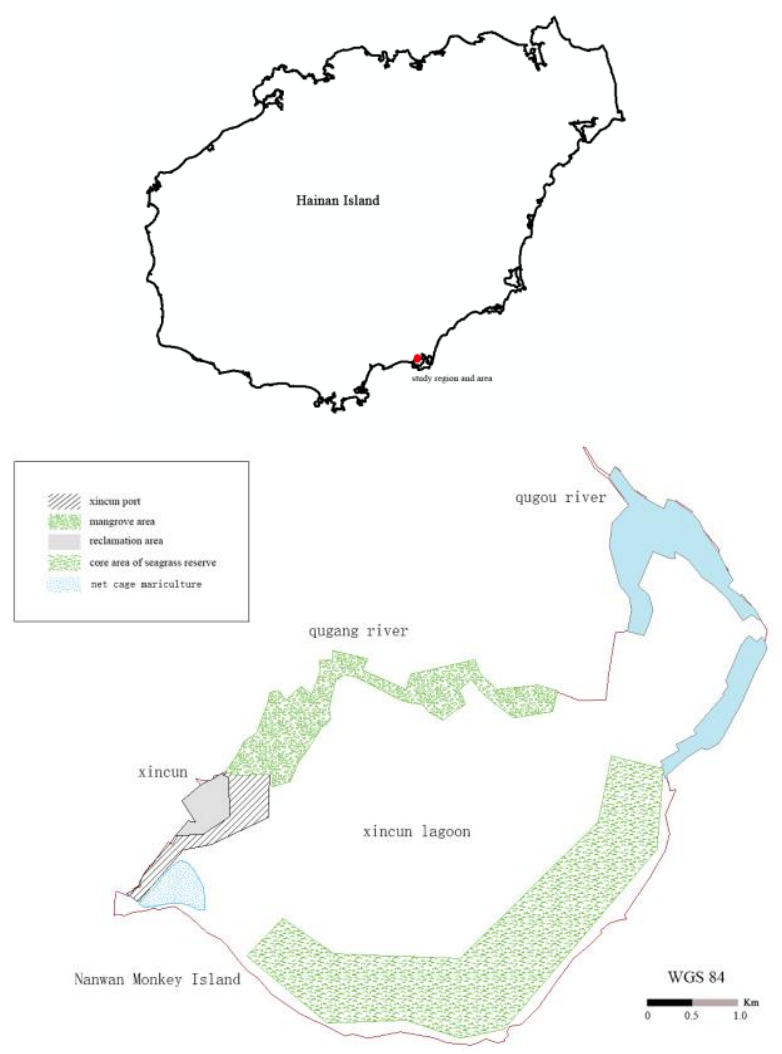

Figure 1. Map of study region and area

\section{Methods}

\section{Index selection}

The rationality of index selection is the basis of determining the rationality of the results of suitability analysis of shallow sea cage culture. In this paper, indicators are chosen according to the following three principles, including (a) reducing the maritime 
conflicts in other human activities in the region, (b) reducing the pressure on Xincun Lagoon ecosystem caused by aquaculture activities and (c) improving the yield and efficiency of mariculture as much as possible. Specific indicators are explained as follows:

(1) The relations with protected areas. According to the requirements of the Planning of seagrass bed special protection area in New Village port, the Seagrass Bed Reserve is divided into general area and core area. The core area requires prohibition of all human activities, which is a prohibitive index. Other areas of the reserve belong to compatible fisheries and aquaculture, as shown in Fig. 2.

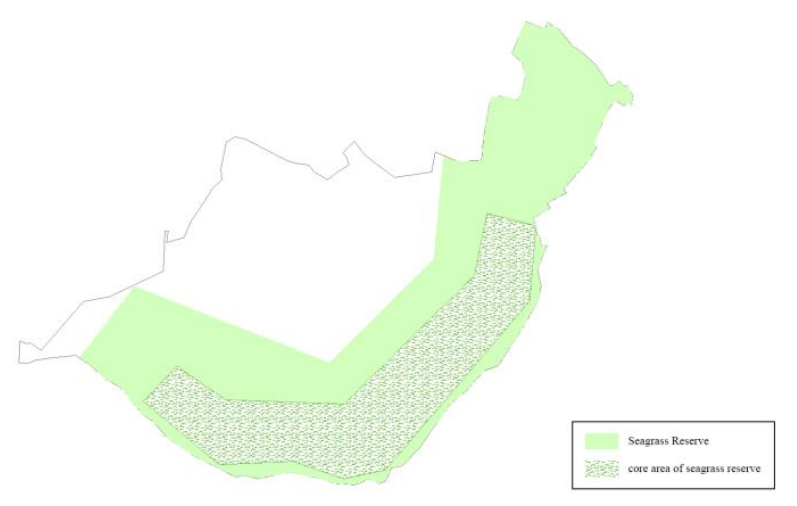

Figure 2. Scope of Seagrass Bed Reserve

(2) The water depth condition. The cage culture needs certain water depth conditions. According to the survey, the local cage depth is about $1.5 \mathrm{~m}$. Thus, if the water is too shallow, the cage culture will not work properly.

(3) The hydrodynamic conditions. The self-purification ability of water body is the main factor to ensure that no major environmental problems occur in aquaculture. In this paper, the semi-exchange ability of water body is selected as the hydrodynamic evaluation index. The stronger the semi-exchange ability of water body is, the better the hydrodynamic conditions are, so it is more suitable for aquaculture activities. The semiexchange ability of water body is shown in Fig. 3.

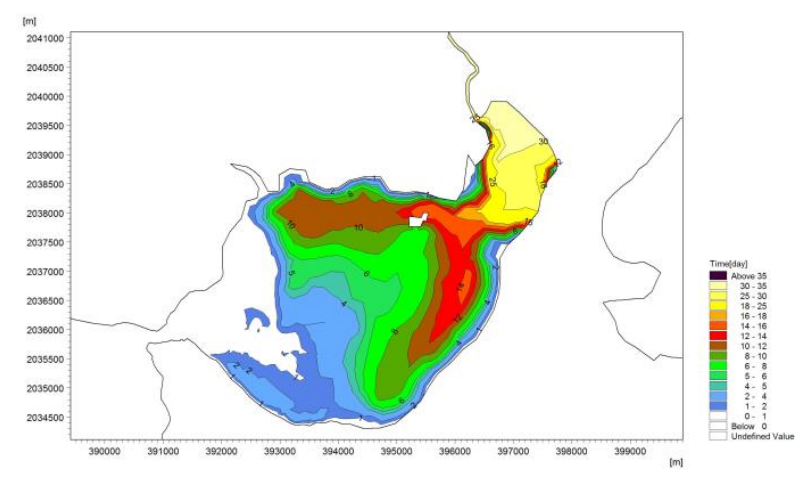

Figure 3. Semi-exchange time of water body

(4) Dissolved oxygen content. Considering the phenomenon of fish death caused by hypoxia in the history of Lagoon, dissolved oxygen content was selected as an index to 
determine the suitability of mariculture in this paper. The higher dissolved oxygen content, the more suitable for aquaculture activities.

(5) Water environment quality. The quality of water environment is one of the important factors to decide whether it is suitable for aquaculture. Good water environment can effectively improve the yield of aquaculture. In this paper, eutrophication index is selected to represent the water environment quality. The higher the degree of eutrophication, the worse the water environment quality.

(6) Terrigenous pollution intensity. There are many human activities around the study area, and a large number of pollutants are discharged directly from the land to the sea. Therefore, the direct discharging area should be kept away from as far as possible to avoid the influence of pollutants on aquaculture.

(7) Wind and wave condition. Because of the small size of shallow sea cages and the weak ability to withstand wind and wave, the areas with smaller wind and wave should be selected for aquaculture.

\section{Determination of index weight values}

This study used the interaction matrix method to calculate the index weight value. Taking the $3^{*} 3$ matrix as shown in Table 1 as an example, all the main factors related to the problem listed on the main diagonal of the square matrix (i. e. $\mathrm{A} \rightarrow \mathrm{C}$ ), and their state variables possess conceptual attributes. Spaces on the non-diagonal lines of the matrix are assigned a value which can be obtained through the numerical analysis, empirical judgment or experimental research to describe the degree of interaction between the two parameters. The interaction matrix shows asymmetry, such as the effect of A on B can be different from the effect of B on A. Analysis and assignment of influences in a strict clockwise direction after the matrix is established.

Table 1. Basic principles of rock engineering systems

\begin{tabular}{c|c|c}
\hline A & The effect of A on B & The effect of A on C \\
\hline The effect of B on A & B & The effect of B on C \\
\hline The effect of C on A & The effect of C on B & C \\
\hline
\end{tabular}

When the interaction matrix is built and encoded, the coded values of the matrix rows and columns are added to determine the degree of interaction of each variable in the system, as shown in Eq.1. The sum of each row represents the effect of the parameters on the main diagonal of the row on the system, while the sum of each column refers to the effect of the system on the parameters on the main diagonal of the column. The higher the degree of interaction is, the greater the importance of this parameter in the system plays, so the interaction matrix can be used to determine the weight of each relevant parameter in the studied system. The weight of the parameter $k_{i}$ can be calculated by from Eq.2 to Eq.4:

$$
\mathrm{V}=\left(\begin{array}{cccccc}
V_{11} & V_{12} & \cdots & V_{1 \mathrm{j}} & \cdots & V_{1 \mathrm{~m}} \\
V_{21} & V_{22} & \cdots & V_{2 \mathrm{j}} & \cdots & V_{2 \mathrm{~m}} \\
\ldots & \cdots & \cdots & \ldots & \cdots & \ldots \\
V_{i 1} & V_{i 2} & \cdots & V_{\mathrm{ij}} & \cdots & V_{\mathrm{im}} \\
\cdots & \cdots & \cdots & \cdots & \cdots & \cdots \\
V_{\mathrm{m} 1} & V_{m 2} & \cdots & V_{\mathrm{mij}} & \cdots & V_{\mathrm{mm}}
\end{array}\right)
$$




$$
\begin{gathered}
k_{i}=\frac{s_{R}(i)+s_{C}(i)}{2 \sum_{i=1 j}^{n} V_{1}^{n} V_{i j}},(i=1,2, \cdots, m) \\
S_{R}(i)=\sum_{i=1}^{m} V_{i j},(i=1,2, \cdots, m) \\
S_{C}(i)=\sum_{j=1}^{m} V_{i j},(i=1,2, \cdots, m)
\end{gathered}
$$

where, in Formula (3) and (4), $V_{i j}$ is the influence degree of parameter $i$ on parameter $i$; $S_{R}(i)$ and $S_{c}(i)$ represent the sum of the elements of each row, and column respectively in the multi-factor interaction matrix. The sum of each row represents the effect of the influence factor in the main diagonal line of the row, and the effect of the factor on the whole system by affecting other influence factors; the sum of each column refers to the effect of the influence factor in the main diagonal line of the column, and the effect of the factor affected by other factors on the entire system.

\section{Weighted stacking}

The comprehensive index of suitability evaluation can be calculated by the following weighted model:

$$
S=\sum_{i=1}^{n} B_{i} W_{i}
$$

where, $S$ is the comprehensive evaluation index of suitability of net cage mariculture in the shallow sea; $B_{i}$ refers to the score of the ith evaluation factor (which is dimensionless); $W_{i}$ denotes the weight of the ith evaluation factor; $n$ refers to the number of factors in the evaluation.

\section{Results}

\section{Index space quantization}

The spatial distributions of each index on ArcGIS are displayed in Fig. 4 to Fig. 10.

(1) Relationships to the conservation area

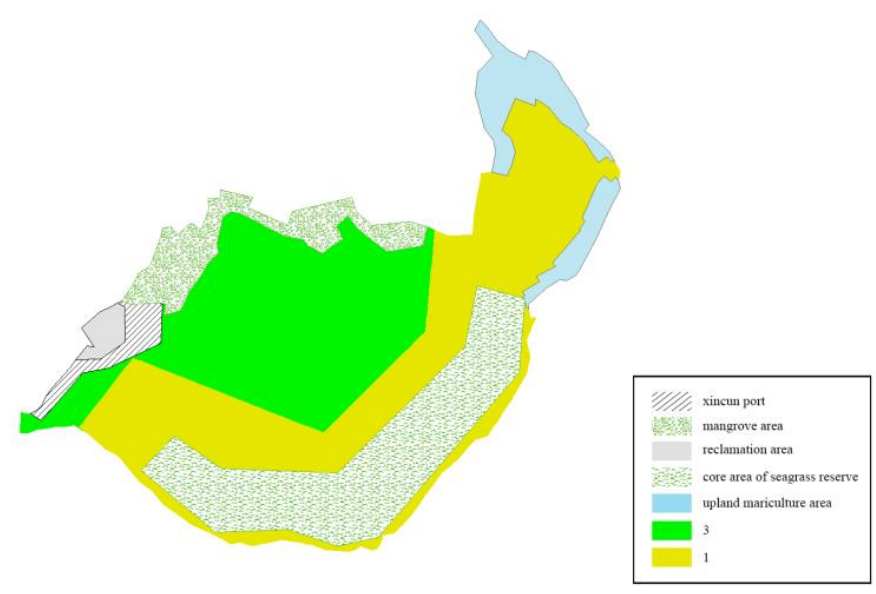

Figure 4. The spatial distributions of "relationships to the conservation area" on ArcGIS 
(2) Hydrodynamic conditions

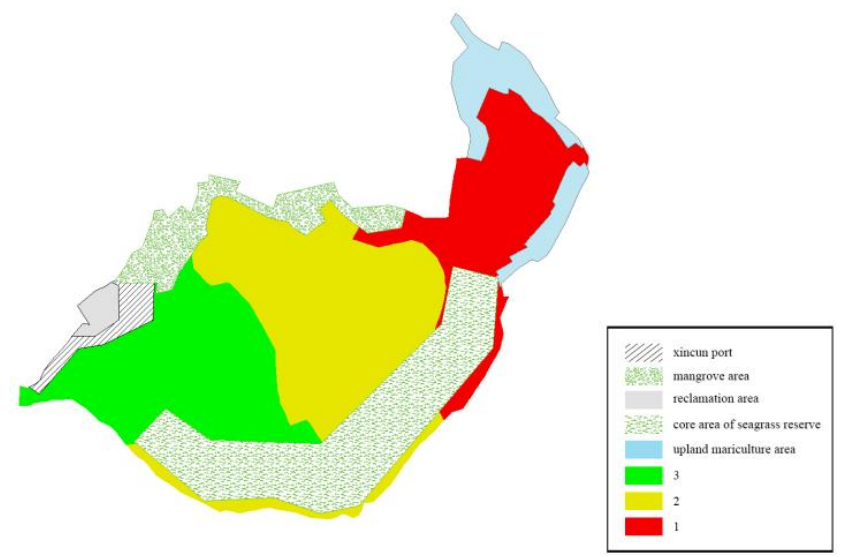

Figure 5. The spatial distributions of "hydrodynamic conditions" on ArcGIS

(3) Land-based pollution intensity

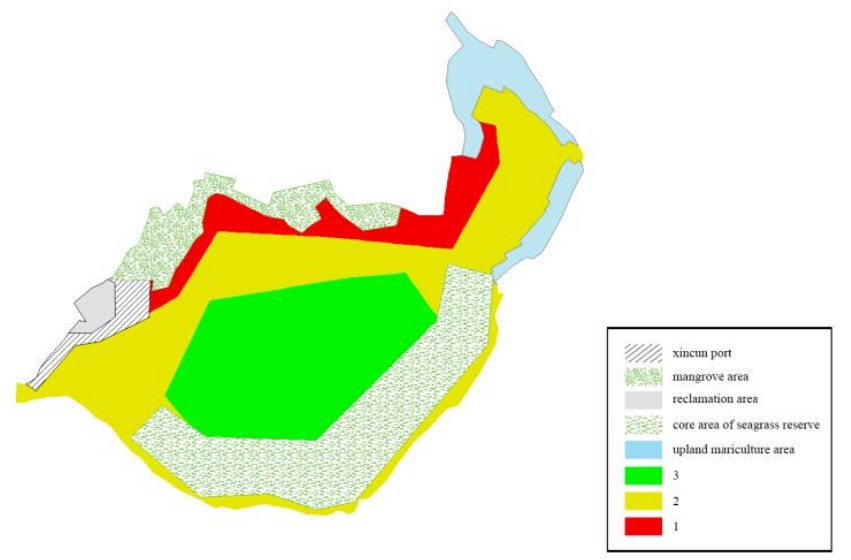

Figure 6. The spatial distributions of "land-based pollution intensity" on ArcGIS

(4) Suitability of water depth

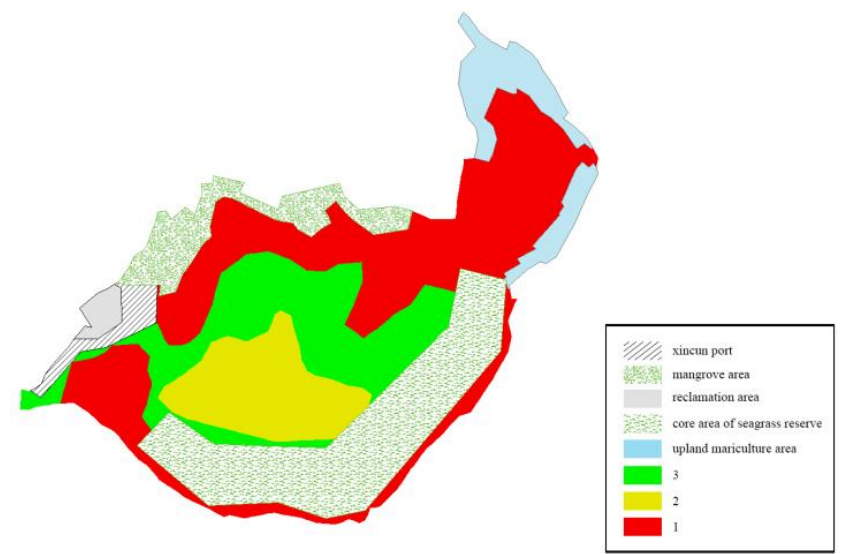

Figure 7. The spatial distributions of "suitability of water depth" on ArcGIS

APPLIED ECOLOGY AND ENVIRONMENTAL RESEARCH 17(3): 6669-6679.

http://www.aloki.hu • ISSN 15891623 (Print) • ISSN 17850037 (Online)

DOI: http://dx.doi.org/10.15666/aeer/1703_66696679

(C) 2019, ALÖKI Kft., Budapest, Hungary 
(5) Water environmental quality

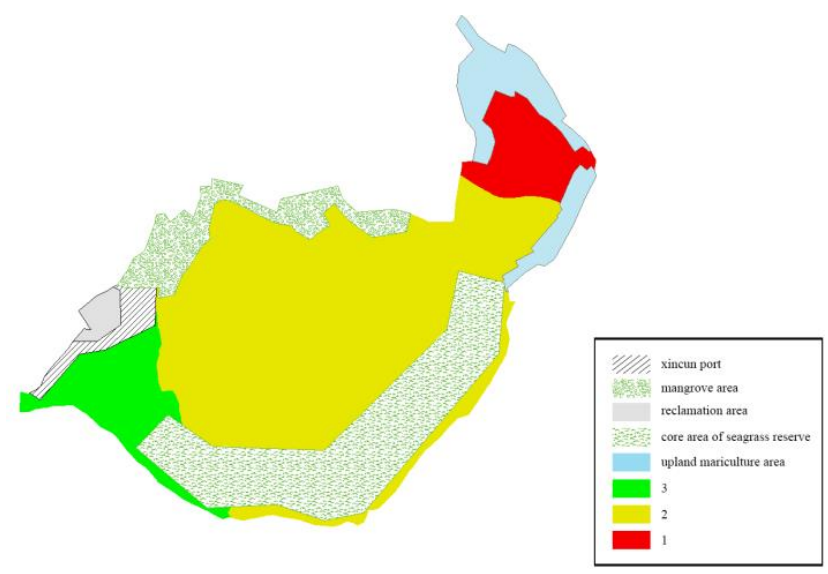

Figure 8. The spatial distributions of "water environmental quality" on ArcGIS

(6) Dissolved oxygen content

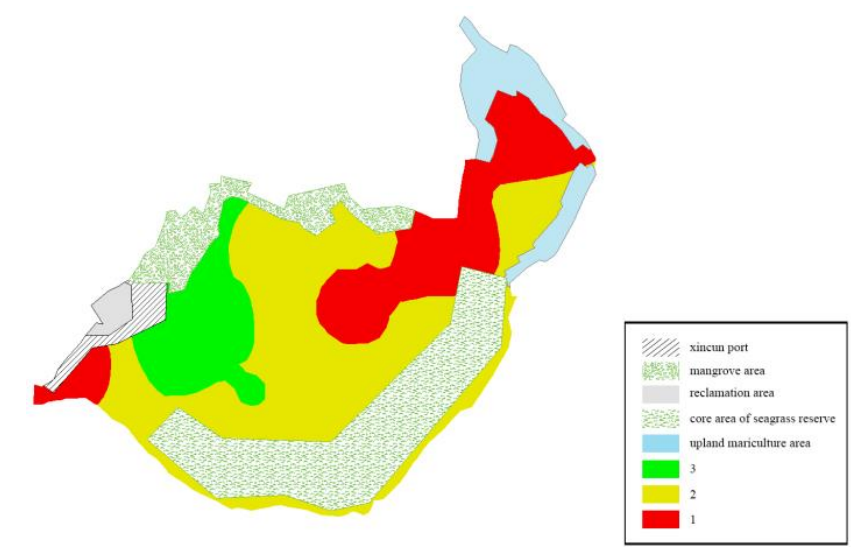

Figure 9. The spatial distributions of "dissolved oxygen content" on ArcGIS

(7) Status of flows and waves

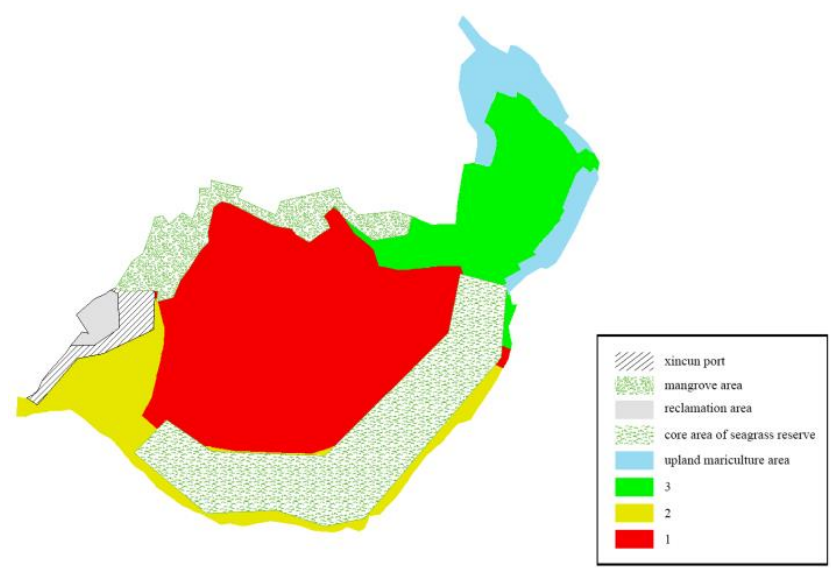

Figure 10. The spatial distributions of "status of flows and waves" on ArcGIS

APPLIED ECOLOGY AND ENVIRONMENTAL RESEARCH 17(3): 6669-6679.

http://www.aloki.hu • ISSN 15891623 (Print) • ISSN 17850037 (Online)

DOI: http://dx.doi.org/10.15666/aeer/1703_66696679

(c) 2019, ALÖKI Kft., Budapest, Hungary 


\section{Calculation of indices}

According to the previous steps, the interaction matrix of suitability of net cage mariculture in the shallow sea was constructed, as shown in Table 2. The degrees of influence between the evaluation indices were divided into 5 levels, represented by the four dimensionless values 0 to 4 respectively: 0 means no effect; 1 indicates weak influence; 2 refers to big influence; 3 represents strong influence; 4 means extremely strong influence.

Table 2. Values of influence degrees of influence factors and their interactions

\begin{tabular}{c|c|c|c|c|c|c}
\hline$(1) 1$ & 0 & 3 & 0 & 3 & 2 & 0 \\
\hline 3 & $(2) 3$ & 0 & 0 & 3 & 2 & 0 \\
\hline 3 & 0 & $(3) 2$ & 0 & 3 & 3 & 0 \\
\hline 0 & 2 & 0 & $(4) 1$ & 1 & 0 & 2 \\
\hline 2 & 0 & 0 & 0 & $(5) 2$ & 2 & 0 \\
\hline 2 & 0 & 0 & 0 & 1 & $(6) 3$ & 0 \\
\hline 0 & 3 & 0 & 0 & 2 & 2 & $(7) 2$ \\
\hline
\end{tabular}

The interaction matrix $V$ of the suitability evaluation factors of net cage mariculture in the shallow sea is as follows:

$$
V=\left(\begin{array}{lllllll}
1 & 0 & 3 & 0 & 3 & 2 & 0 \\
3 & 3 & 0 & 0 & 3 & 2 & 0 \\
3 & 0 & 2 & 0 & 3 & 3 & 0 \\
0 & 2 & 0 & 1 & 1 & 0 & 2 \\
2 & 0 & 0 & 0 & 2 & 2 & 0 \\
2 & 0 & 0 & 0 & 1 & 3 & 0 \\
0 & 3 & 0 & 0 & 2 & 2 & 2
\end{array}\right)
$$

Based on Eq.2 to Eq.4, the weights $W_{i}$ of these seven influence factors can be calculated.

The weight of relationships to the conservation area $W_{1}$ was calculated as 0.1724 , the hydrodynamic conditions $W_{2}$ as 0.1639 , the land-based pollution intensity $W_{3}$ as 0.1379 , the suitability of water depth $W_{4}$ as 0.0603 , the water environmental quality $W_{5}$ as 0.1810 , the dissolved oxygen content $W_{6}$ as 0.1724 , and the status of flows and waves $W_{7}$ as 0.1121 .

$\mathrm{C}$, the sum of the row values, and $\mathrm{E}$, the sum of the column values, $\mathrm{C}+\mathrm{E}$ represents the value of interaction strength of each principal factor. The larger the value is, the stronger the importance of the parameter is; $\mathrm{C}-\mathrm{E}$ indicates the dominance of each principal factor. $\mathrm{C}-\mathrm{E}$ is greater than 0 , indicating that the parameter is dominant, while $\mathrm{C}$-E is less than 0 , implying that the parameter is dependent. The detailed relationships are displayed in Table 3.

Table 3. Relationship parameters between $C$ and $E$

\begin{tabular}{c|c|c|c|c|c|c|c}
\hline Relationship of C and E & $\boldsymbol{V}_{\mathbf{1}}$ & $\boldsymbol{V}_{\mathbf{2}}$ & $\boldsymbol{V}_{\mathbf{3}}$ & $\boldsymbol{V}_{\mathbf{4}}$ & $\boldsymbol{V}_{\mathbf{5}}$ & $\boldsymbol{V}_{\mathbf{6}}$ & $\boldsymbol{V}_{\mathbf{7}}$ \\
\hline $\mathrm{C}$ & 9 & 11 & 11 & 6 & 6 & 6 & 9 \\
\hline $\mathrm{E}$ & 11 & 8 & 5 & 1 & 15 & 14 & 4 \\
\hline $\mathrm{C}+\mathrm{E}$ & 20 & 19 & 16 & 7 & 21 & 20 & 13 \\
\hline $\mathrm{C}-\mathrm{E}$ & -2 & 3 & 6 & 5 & -9 & -8 & 5 \\
\hline
\end{tabular}




\section{Implementation of weighted stacking on ArcGIS}

On the basis of the calculation according to Eq.5 by using ArcGIS10.0 and the spatial quantitative analysis, the spatial distribution of the suitability of mariculture in the shallow sea on ArcGIS can be obtained (Fig. 11). It can be seen that the most suitable area for net cage mariculture in the shallow sea is located at the mouth of the gate, accounting for about $10.00 \%$ of the total sea area, while the most unsuitable area for net cage mariculture in the shallow sea stands in the secondary bay, covering approximately $13.04 \%$ of the total sea area.

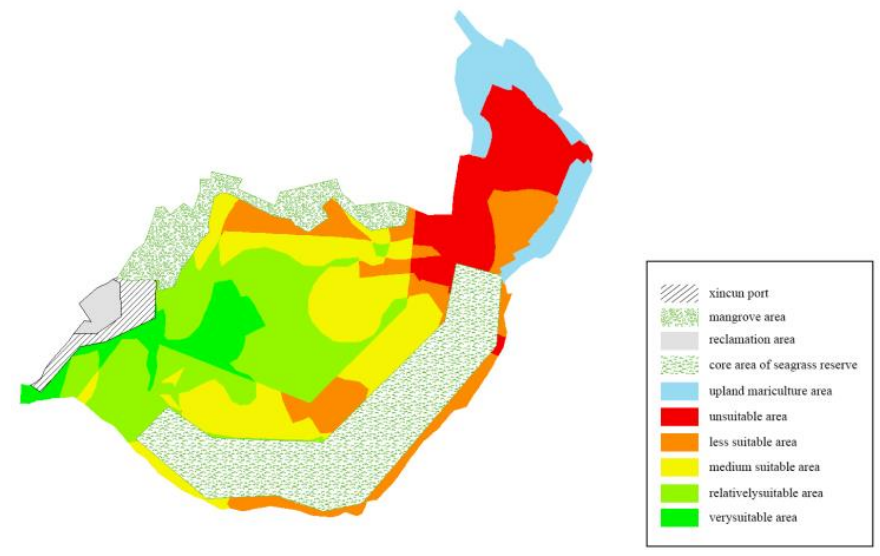

Figure 11. The spatial distributions of suitability of mariculture in the shallow sea on ArcGIS

\section{Conclusions}

On the above research, it can be determined that the areas suitable for shallow sea net cage mariculture in the Xincun Lagoon are mainly located at Area of 1, 2 and 3 (Fig. 12). However, this paper did not take into account factors such as social economy and transportation services in selecting the indicators. Unlike other cage cultures, farmers in the region live in shelters built by cages on the water. Therefore, the site selection should also consider the convenience of transportation to surrounding towns. For the spatial distance, Area 1 demonstrates as the most suitable one, and in fact, it is more conforming with the current farming situation.

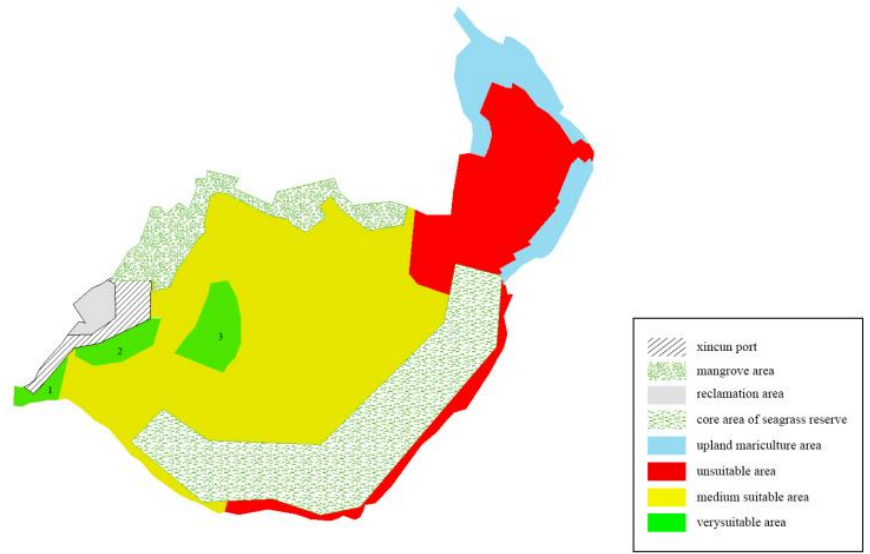

Figure 12. The simplified distribution of suitable area for mariculture in the shallow sea 
This paper can clarify the suitable area for net cage mariculture in the shallow sea, but the accumulation of a large number of cages will cause changes in hydrodynamic conditions in the surrounding waters, as well as pollutants. Thus, further research is required to determine the division and layout of the cages to minimize the pressure on the ecosystem in the lagoon.

The interaction matrix can consider the interactions between the factors and calculate the affiliation of the factors. The results show that hydrodynamic conditions, the landbased pollution intensity, the suitability of water depth, and the status of water flows and waves are the dominant parameters, all of which are the driving factors for system changes. Although the conclusions of this study are highly credible, the dynamic changes of the indicators are not taken into account in the calculation process. In the future research work, the changes of the dominating parameters should be focused on and adjusted at any time.

Acknowledgements. This work was supported by Scientific Research Fund of the Second Institute of Oceanography, MNR, grant No. JG1917.

\section{REFERENCES}

[1] Dapueto, G., Massa, F., Costa, S., Cimoli, L., Olivari, E., Chiantore, M., Federici, B., Povero, P. (2015): A spatial multi-criteria evaluation for site selection of offshore marine fish farm in the Ligurian sea, Italy. - Ocean \& Coastal Management 116: 64-77.

[2] Fang, X., Hao, C. L., Cheng, C. G., Ni, W., Wang, J. C., Zhang, Y. F. (2018): Pressure analysis and spatial quantitative assessment of impact of human activities on Lagoon ecosystem: a case study in Xincun and Li'an Lagoons, Hainan, China. - Applied Ecology And Environmental Research 16(5): 6253-6266.

[3] FAO. (2015): Aquaculture Zoning, Site Selection and Area Management under the Ecosystem Approach to Aquaculture. - Policy brief.

[4] Hudson, J. A. (1989): Rock mechanics principle in engineering practice. - CIRIA Ground Engineering Report: Underground Construction.

[5] Joaquin, B. (2011): A Single-Use Site Selection Technique, Using GIS, for Aquaculture Planning: Choosing Locations for Mangrove Oyster Raft Culture in Margarita Island, Venezuela. - Site Selection Technique for Aquaculture Planning.

[6] Mazzoccola, D. F., Hudson, J. A. (1996): A comprehensive method of rock mass characterization for indicating natural slope instability. - Quarterly Journal of Engineering Geology and Hydrogeology 29(1): 37-56.

[7] Parker, M. R., Beal, B. F., Congleton Jr, W. R., Pearce, B. R., Morin, L. (1998): Utilization of GIS and GPS for shellfish grow out site selection. - J. Shellfish Res. 17: 1491-1495.

[8] Velasco, H. R., Ayub, J. J., Belli, M., Sansone, U. (2006): Interaction matrices as a first step toward a general model of radionuclide cycling: application to the $137 \mathrm{Cs}$ behavior in a grassland ecosystem. - Journal of Radioanalytical and Nuclear Chemistry 268: 503-509.

[9] Wu, H. G., Ma, H. M., Zhang, H. L. (2011): Evaluation of subgrade stability of mountainous highway exhibition based on interaction matrix. - Chinese Journal of Geotechnical Engineering 33(S1): 209-213.

[10] Yin, S., Takeshige, A., Miyake, Y., Kimura, S. (2018): Selection of suitable coastal aquaculture sites using multi-criteria decision analysis in Menai Strait, UK. - Ocean \& Coastal Management 165: 268-279.

[11] Zhou, Q., Herrera, J., Hidalgo, A. (2017): Development of a quantitative assessment approach for the coal and gas outbursts in coal mines using rock engineering systems. - International Journal of Mining Reclamation \& Environment, DOI:10.1080/17480930.2017.1326077. 